\title{
The impact of failure to achieve symptom control after resection of functional neuroendocrine tumors: An 8-institution study from the US Neuroendocrine Tumor Study Group
}

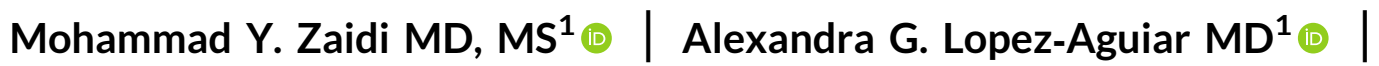 \\ George A. Poultsides $\mathrm{MD}^{2}$ | Mary Dillhoff $\mathrm{MD}^{3}$ | Flavio G. Rocha $\mathrm{MD}^{4}$ | \\ Kamran Idrees $\mathrm{MD}^{5}$ | Hari Nathan MD, $\mathrm{PhD}^{6}$ | Emily R. Winslow $\mathrm{MD}^{7}$ | \\ Ryan C. Fields $\mathrm{MD}^{8} \mid$ Kenneth Cardona $\mathrm{MD}^{1}{ }^{1}$ । |
}

Shishir K. Maithel MD ${ }^{1}$ and other members of the US Neuroendocrine Tumor Study Group

\footnotetext{
${ }^{1}$ Division of Surgical Oncology, Department of Surgery, Winship Cancer Institute, Emory University, Atlanta, Georgia

${ }^{2}$ Department of Surgery, Stanford University Medical Center, Stanford, California

${ }^{3}$ Division of Surgical Oncology, The Ohio State University Comprehensive Cancer Center, Columbus, Ohio

${ }^{4}$ Department of Surgery, Virginia Mason Medical Center, Seattle, Washington

${ }^{5}$ Division of Surgical Oncology, Department of Surgery, Vanderbilt University Medical Center, Nashville, Tennessee

${ }^{6}$ Division of Hepatopancreatobiliary and Advanced Gastrointestinal Surgery,

Department of Surgery, University of

Michigan, Ann Arbor, Michigan

${ }^{7}$ Department of Surgery, University of Wisconsin School of Medicine and Public Health, Madison, Wisconsin

${ }^{8}$ Department of Surgery, Washington University School of Medicine, St Louis, Missouri
}

\section{Correspondence}

Shishir K. Maithel, MD, FACS, Associate Professor of Surgery, Scientific Director, Emory Liver and Pancreas Center, Winship Cancer Institute, Division of Surgical Oncology, Department of Surgery, Emory University, 1365C Clifton Road, NE; Building C, 2nd Floor, Atlanta, GA 30322.

Email: smaithe@emory.edu
Background: The goals of resection of functional neuroendocrine tumors (NETs) are two-fold: Oncological benefit and symptom control. The interaction between the two is not well understood.

Methods: All patients with functional NETs of the pancreas, duodenum, and ampulla who underwent curative-intent resection between 2000 and 2016 were identified. Using Cox regression analysis, factors associated with reduced recurrence-free survival (RFS) were identified.

Results: Two-hundred and thirty patients underwent curative-intent resection. Fiftythree percent were insulinomas, 35\% gastrinomas, and 12\% were other types. Twenty-one percent had a known genetic syndrome, $23 \%$ had lymph node (LN) positivity, $80 \%$ underwent an R0 resection, and $14 \%$ had no postoperative symptom improvement (SI). Factors associated with reduced RFS included noninsulinoma histology, the presence of a known genetic syndrome, LN positivity, R1 margin, and lack of SI. On multivariable analysis, only the failure to achieve SI following resection was associated with reduced RFS. Considering only those patients with an RO resection, failure to achieve SI was associated with worse 3-year RFS compared with patients having SI (36\% vs $80 \% ; P=0.006)$.

Conclusions: Failure to achieve symptomatic improvement after resection of functional NETs is associated with worse RFS. These patients may benefit from short-interval surveillance imaging postoperatively to assess for earlier radiographical disease recurrence.

KEYWORDS

gastrinoma, glucagonoma, insulinoma, recurrence, symptomatic, VIPoma 


\section{1 | INTRODUCTION}

Neuroendocrine tumors (NETs) consist of a heterogeneous group of tumors with distinct molecular, histological, and clinical features with complex and often challenging management strategies. ${ }^{1}$ These tumors are traditionally divided as either functional or nonfunctional: Functional NETs produce peptide hormones which cause symptoms, while nonfunctional NETs are typically clinically silent until they produce mass effect or bleed. Functional NETs are comprised of several histological types. In sporadic cases, the most common type is insulinoma, followed by gastrinoma and other types including glucagonoma, VIPoma, and somatostatinoma. ${ }^{2}$ Each type is characterized by a discrete secretory phenotype and a predictable clinical syndrome. ${ }^{3}$ The otherwise distinguishable clinical syndromes, however, can become muddied when functional NETs occur in the background of a hereditary tumor syndrome. These tumor syndromes, the most common being multiple endocrine neoplasia-I (MEN-I), provide unique challenges in the management of these patients. $^{4-10}$

For both sporadic and hereditary functional NETs, surgical resection provides the only potential for cure in patients with locoregional disease. Although NETs are generally indolent tumors, many patients undergo resection to relieve the clinical symptoms associated with functional NETs. ${ }^{11}$ Aside from insulinomas which are commonly treated with enucleation, most functional NETs require a wide oncological resection with regional lymphadenectomy to achieve cure. ${ }^{12,13}$ Curative oncological resection, however, is not always possible, as many patients present with distant disease due to the propensity of these tumors to metastasize to the liver. Yet even in the metastatic setting, multiple groups have demonstrated that resection of liver metastases, cytoreductive surgery, and local ablative therapy may be associated with improved survival and alleviate symptoms of functional NETs. ${ }^{14-16}$ These findings suggest a potential interaction between the relief of clinical symptoms of functional NETs, known as oncological parameters, disease recurrence, and survival.

Little information is available regarding the relationship between the achievement of hormone-specific symptom control and oncological benefit after the surgery for functional neuroendocrine tumors. The aim of this study is to use a large, multi-institutional database to define the association between the failure to achieve symptom improvement after the surgical resection for functional neuroendocrine tumors and clinical outcomes. We also aimed to determine other clinicopathological factors associated with worse outcomes for functional NETs. Lastly, we aimed to establish the prognostic value of symptom improvement compared with other known oncological parameters.

\section{2 | METHODS}

Patients were identified using the United States Neuroendocrine Tumor Study Group (US-NETSG), a collaborative of 8 US-based institutions (Emory University, The Ohio State University, Stanford University, Virginia Mason University, Vanderbilt University, University of Michigan, University of Wisconsin, and Washington University in St. Louis). Institutional Review Board (IRB) approval was obtained at each institution. All patients who underwent curativeintent surgical resection of a functional NET of the pancreas, duodenum, or ampulla between 2000 and 2016 were included. Functional tumor status was defined by clinical and histopathological diagnoses of insulinoma, gastrinoma, glucagonoma, somatostatinoma, or VIPoma. Symptomatic nonfunctional NETs with a carcinoid syndrome were excluded. Patients with genetic tumor syndromes were included, specifically MEN-I, Von Hippel-Lindau disease, neurofibromatosis 1 , and tuberous sclerosis. Final resection status was defined as RO (complete gross tumor clearance with negative microscopic margins), R1 (complete gross tumor clearance with positive microscopic margins), and R2 (incomplete gross tumor clearance). Patients with mortality less than 30 days after the surgery were excluded.

Data on demographics, perioperative conditions, and histopathology were collected. Pathology was reviewed by expert gastrointestinal (GI) pathologists at each institution. Staging was based on the American Committee on Cancer (AJCC) 7th edition guidelines. ${ }^{17}$ Recurrence-free survival (RFS) data were collected from the electronic medical record. Disease recurrence was defined strictly as the radiographical recurrence of disease.

The primary aim was to assess the association between clinicopathological variables and decreased RFS. The failure of symptom improvement, defined as the patient-reported lack of clinical symptom improvement after the surgery, was of particular interest. Symptoms were specifically related to the secretory phenotype of the resected functional tumor, as recorded in postoperative visit documentation in the electronic medical record.

All statistical analysis was conducted using SPSS 22.0 software (IBM Inc., Armonk, NY). Chi-squared analysis was used to compare categorical variables, and Student $t$-test was used for continuous variables. Univariate and multivariable Cox regression analyses were used to determine the association of the variables of interest with reduced RFS. All variables which correlated with reduced RFS at statistical significance of $P<0.1$ on univariate analysis were included in the multivariable model. Kaplan-Meier survival plots for RFS were constructed to compare patients with and without symptom improvement after surgery. Statistical significance was defined as $P<0.05$.

\section{RESULTS}

\section{1 | Demographics}

Of 2181 total patients within the US-NETSG database, 230 patients underwent curative-intent resection of a functional NET. Demographic characteristics are listed in Table 1. Average age was $52.4( \pm 15.3)$ years and $110(47.8 \%)$ patients were male. Forty-eight (20.9\%) patients had functional tumors associated 
TABLE 1 Demographic characteristics of patients with functional neuroendocrine tumors within the US- Neuroendocrine Tumor Study Group database

\begin{tabular}{|ll}
\hline Baseline variable & $\mathbf{n}(\%)$ \\
\hline Age (y), mean \pm SD & $52.4 \pm 15.3$ \\
Male & $110(47.8)$ \\
BMI, mean \pm SD & $29.1 \pm 6.9$ \\
\hline Race & \\
White & $173(75.2)$ \\
Black & $21(9.1)$ \\
Latino & $11(4.8)$ \\
\hline Functional status & \\
Independent & $184(80.0)$ \\
Partially dependent & $11(4.8)$ \\
\hline Genetic syndrome & $48(20.9)$ \\
MEN-I & $41(17.8)$ \\
Neurofibromatosis-1 & $1(0.4)$ \\
Other & $6(2.6)$ \\
\hline Type of functional tumor & \\
Insulinoma & $122(53.0)$ \\
Gastrinoma & $80(34.8)$ \\
Glucagonoma & $11(4.8)$ \\
VIPoma & $10(4.3)$ \\
Somatostatinoma & $3(1.3)$ \\
Other & $4(1.7)$ \\
\hline
\end{tabular}

Abbreviation: MEN-I, multiple endocrine neoplasia type 1.

with a hereditary tumor syndrome, the most common being MENI. The majority of the functional tumors were insulinomas (122, $53 \%)$, followed by gastrinomas $(80,34.8 \%)$, and glucagonomas (11, 4.8\%).

\section{2 | Perioperative data and pathology}

The most frequent location for a functional NET in this cohort was in the pancreas (194, 84.3\%), followed by the duodenum (26, 11.3\%). Perioperative and pathological characteristics are listed in Table 2. One-hundred and two (44\%) patients underwent enucleation of their tumors, 26 of whom had lymph node retrieval with enucleation, and 128 (56\%) patients underwent anatomic resection. There was no difference in RFS between patients who underwent enucleation versus those who underwent anatomic resection $(P=0.152)$. The majority of patients had well-differentiated tumors (181 patients, $78.7 \%$ ) with a $\mathrm{Ki}-67$ of less than $3 \%(92,40 \%)$. Final resection status was RO for 184 (80\%) patients and R1 for 46 (20\%) patients. Radiographical surveillance strategies varied among patients with 35 (15\%) patients undergoing cross-sectional imaging at every 3 to 4 months, 73 (32\%) patients at every 6 months-1 year, 2 (1\%) patients at greater than once per year, and 120 (52\%) patients undergoing no set surveillance strategy or an unknown surveillance strategy. Postoperatively, 108 (47\%) patients experienced symptom improvement, 17 (7.4\%) did not experience symptom improvement, and 105 (45.7\%) of patients had unknown symptom improvement
TABLE 2 Perioperative and pathological characteristics of patients with functional neuroendocrine tumors within the USNeuroendocrine Tumor Study Group database

\begin{tabular}{|c|c|}
\hline Pathological variable & n (\%) \\
\hline \multicolumn{2}{|l|}{ Operative intent } \\
\hline Curative & $230(100.0)$ \\
\hline \multicolumn{2}{|l|}{ Type of resection } \\
\hline Enucleation alone & $76(33.0)$ \\
\hline Enucleation with lymph node retrieval & $26(11.3)$ \\
\hline Anatomic resection & $128(55.7)$ \\
\hline Multifocal tumors & $31(16.1)$ \\
\hline Tumor size $(\mathrm{cm})$, median (IQR) & $1.7(1.2-2.5)$ \\
\hline \multicolumn{2}{|l|}{ Tumor location } \\
\hline Pancreas & $194(84.3)$ \\
\hline Duodenum & $26(11.3)$ \\
\hline Liver & $5(2.2)$ \\
\hline Ampulla & $5(2.2)$ \\
\hline \# Tumors, median (IQR) & $1(1-1)$ \\
\hline \multicolumn{2}{|l|}{ Tumor differentiation } \\
\hline Well & $181(78.7)$ \\
\hline Moderate & $9(3.9)$ \\
\hline \multicolumn{2}{|l|}{ Ki-67 } \\
\hline$<3 \%$ & $92(40.0)$ \\
\hline $3 \%-20 \%$ & $40(17.4)$ \\
\hline$>20 \%$ & $3(1.3)$ \\
\hline Unknown & $113(43.5)$ \\
\hline LVI & $48(20.9)$ \\
\hline PNI & $16(7.0)$ \\
\hline Lymph node positive & $52(22.6)$ \\
\hline \# Lymph nodes positive, median (IQR) & $0(0-1)$ \\
\hline \multicolumn{2}{|l|}{ Final resection status } \\
\hline RO & $184(80.0)$ \\
\hline $\mathrm{R} 1$ & $46(20.0)$ \\
\hline Postoperative variable & n (\%) \\
\hline Any complication & $118(51.3)$ \\
\hline Clavien-Dindo 1 & $26(11.3)$ \\
\hline Clavien-Dindo 2 & $33(14.3)$ \\
\hline Clavien-Dindo $\geq 3$ & $59(25.7)$ \\
\hline \multicolumn{2}{|l|}{ Symptom improvement } \\
\hline Yes & $108(47.0)$ \\
\hline No & $17(7.4)$ \\
\hline Unknown & $105(45.7)$ \\
\hline Reoperation & $11(4.8)$ \\
\hline Readmission & $46(20.0)$ \\
\hline Recurrence & $38(16.5)$ \\
\hline
\end{tabular}

Abbreviations: LVI, lymphovascular invasion; PNI, perineural invasion.

following surgery. Median follow-up time was 29.4 months. Of patients with disease recurrence, 12 (32.4\%) had locoregional recurrence, 19 (51.4\%) had distant recurrence, and 6 (16.2\%) patients had both locoregional and distant recurrences. Seventeen patients without symptom improvement after surgery experienced disease recurrence (Table 3). 
TABLE 3 Preoperative and postoperative characteristics of patients without symptom improvement who experienced disease recurrence

\begin{tabular}{|c|c|c|c|c|c|c|c|c|c|c|}
\hline Pt \# & Age (y) & Sex & Type of tumor & $\begin{array}{l}\text { Genetic } \\
\text { syndrome }\end{array}$ & $\begin{array}{l}\text { Type of } \\
\text { resection }\end{array}$ & $\begin{array}{l}\text { Size } \\
(\mathrm{cm})\end{array}$ & $\begin{array}{l}\text { Tumor } \\
\text { location }\end{array}$ & R0/R1 & $\begin{array}{l}\text { Multifocal } \\
\text { recurrence }\end{array}$ & Region of recurrence \\
\hline 1 & 59 & $\mathrm{~F}$ & VIPoma & None & Anatomic & 1.7 & Liver & RO & Yes & Distant \\
\hline 2 & 70 & $M$ & VIPoma & None & Anatomic & 2 & Pancreas & RO & No & Distant \\
\hline 3 & 47 & $M$ & Gastrinoma & Other & Anatomic & 9.1 & Pancreas & RO & Yes & Distant \\
\hline 4 & 52 & $\mathrm{~F}$ & Gastrinoma & None & Anatomic & 1.3 & Pancreas & RO & Yes & - \\
\hline 5 & 33 & $M$ & Gastrinoma & MEN-1 & Anatomic & 11.5 & Pancreas & RO & Yes & Distant \\
\hline 6 & 45 & $\mathrm{~F}$ & Glucagonoma & None & Anatomic & 15.2 & Pancreas & RO & Yes & Locoregional + distant \\
\hline 7 & 52 & $\mathrm{~F}$ & Insulinoma & MEN-1 & Anatomic & 2.0 & Pancreas & RO & No & Locoregional \\
\hline 8 & 38 & $M$ & Insulinoma & None & Anatomic & 4.6 & Pancreas & RO & No & Distant \\
\hline 9 & 63 & $M$ & Insulinoma & None & Anatomic & 12.9 & Pancreas & RO & No & Locoregional + distant \\
\hline 10 & 66 & $\mathrm{~F}$ & Gastrinoma & None & Enucleation & 1.8 & Pancreas & $\mathrm{R} 1$ & Yes & Locoregional \\
\hline 11 & 48 & $M$ & Gastrinoma & MEN-1 & Enucleation & 2.0 & Pancreas & $\mathrm{R} 1$ & - & Locoregional \\
\hline 12 & 44 & $\mathrm{~F}$ & Gastrinoma & None & Enucleation & 1.3 & Duodenum & RO & Yes & Locoregional \\
\hline 13 & 73 & $\mathrm{~F}$ & Gastrinoma & None & Enucleation & 5.5 & Pancreas & RO & No & Distant \\
\hline 14 & 38 & $\mathrm{~F}$ & Gastrinoma & MEN-1 & Enucleation & 1.4 & Duodenum & - & Yes & Locoregional \\
\hline 15 & 42 & $M$ & Glucagonoma & None & Enucleation & 7.5 & Pancreas & RO & No & Distant \\
\hline 16 & 39 & $\mathrm{~F}$ & Insulinoma & None & Enucleation & 1.0 & Pancreas & RO & No & Distant \\
\hline 17 & 91 & $\mathrm{~F}$ & Insulinoma & None & Enucleation & 7.5 & Pancreas & RO & Yes & Distant \\
\hline
\end{tabular}

Abbreviation: MEN-I, multiple endocrine neoplasia type 1.

\subsection{Relationship between symptom improvement and preoperative and pathological factors}

Patients who experienced symptom improvement after surgery were more likely to not have a genetic tumor syndrome $(P=0.001)$, have insulinoma tumor histology $(P=0.014)$, and have an RO resection $(P=0.007)$, as seen in Table 4. Multifocality, tumor differentiation, Ki-67 index, lymph node positivity, and lymphovascular/perineural invasion status were not associated with symptom improvement after the surgery.

\subsection{Symptom improvement and recurrence-free survival}

On univariable analysis, factors associated with reduced RFS were noninsulinoma tumor histology (gastrinoma: $\mathrm{HR} 2.8,95 \% \mathrm{Cl}, 1.3-6.1$, $P=0.006$, other: $\mathrm{HR} 2.7,95 \% \mathrm{Cl}, 1.0-7.2 P=0.042$ ), having a known genetic tumor syndrome ( $\mathrm{HR} 1.8,95 \% \mathrm{Cl}, 0.9-3.5, P=0.077)$, lymph node positivity ( $\mathrm{HR} 1.8,95 \% \mathrm{Cl}, 0.9-3.6, P=0.080$ ), R1 resection margin (HR 2, 95\% Cl, 1.0-3.9, $P=0.052$ ), and failure of symptom improvement after the surgery (HR 3.1, 95\% Cl, 1.3-7.2, $P=0.008$ ) (Table 5). Tumor location, multifocality, and tumor differentiation were not associated with decreased RFS. On multivariable analysis, however, only the failure of symptom improvement was associated with decreased RFS (HR 4.7, 95\% Cl, 1.3-16.6, $P=0.016$ ).

For this entire cohort, patients without symptom improvement had a lower 3-year RFS than patients who did experience symptom improvement $(49.9 \%$ vs $80.3 \%, P=0.005$, Figure $1 \mathrm{~A})$. When considering only patients with RO resections, patients without symptom improvement continued to have a decreased 3-year RFS compared with patients with symptom improvement after surgery ( $36 \%$ vs $80 \%, P=0.006$; Figure $1 B)$.

\section{4 | DISCUSSION}

Functional neuroendocrine tumors are surgically resected for both oncological benefit and for symptom control, but the interaction between the two is not clear. This study found that patients who fail to experience hormone-specific symptom improvement after the surgical resection tend to have worse RFS than those who do experience symptom improvement, even in patients who received an RO resection. When evaluating other variables associated with worse RFS, the failure of symptom improvement persisted as the only factor associated with decreased RFS when considering resection status, lymph node positivity, the presence of a hereditary tumor syndrome, and histological type of tumor. Thus, the failure of symptom improvement after resection may serve as an important clinical indicator for worse prognosis and earlier radiographical recurrence of disease.

NETs tend to be more indolent tumors with a better prognosis compared to other malignancies within the $\mathrm{GI}$ tract. $^{18}$ Compared with nonfunctional NETs, functional NETs are described to carry a better prognosis as they are more likely to present earlier in their disease course with identifiable clinical manifestations. ${ }^{19-21}$ Even with generally favorable outcomes, certain subtypes of functional NETs are aggressive, particularly those with noninsulinoma histology. Gastrinomas cause clinical symptoms leading to significant morbidity, and many patients with gastrinomas have metastatic disease at the 
TABLE 4 Relationship between clinicopathological factors of patients with functional neuroendocrine tumors and postoperative symptom improvement

\begin{tabular}{|c|c|c|c|}
\hline \multirow[b]{2}{*}{ Variable } & \multicolumn{2}{|c|}{ Symptom improvement } & \multirow[b]{2}{*}{$P$ value } \\
\hline & No, $n$ (\%) & Yes, n (\%) & \\
\hline Known genetic syndrome & 9 (52.9\%) & $16(14.8 \%)$ & 0.001 \\
\hline $\begin{array}{l}\text { Type of functional tumor } \\
\text { Insulinoma } \\
\text { Gastrinoma } \\
\text { Other }\end{array}$ & $\begin{array}{l}5(29.4 \%) \\
11(64.7 \%) \\
1(5.9 \%)\end{array}$ & $\begin{array}{l}63(58.3 \%) \\
30(27.8 \%) \\
15(13.9 \%)\end{array}$ & 0.014 \\
\hline Multifocal & $6(35.3 \%)$ & $22(20.4 \%)$ & 0.290 \\
\hline $\begin{array}{l}\text { Tumor location } \\
\text { Pancreas } \\
\text { Duodenum } \\
\text { Liver } \\
\text { Ampulla }\end{array}$ & $\begin{array}{l}12(70.6 \%) \\
4(23.5 \%) \\
0(0 \%) \\
0(0 \%)\end{array}$ & $\begin{array}{l}88(81.5 \%) \\
12(11.1 \%) \\
4(3.7 \%) \\
4(3.7 \%)\end{array}$ & 0.091 \\
\hline $\begin{array}{l}\text { Tumor differentiation } \\
\text { Well } \\
\text { Moderate }\end{array}$ & $\begin{array}{l}13(100 \%) \\
0(0 \%)\end{array}$ & $\begin{array}{l}88(98.9 \%) \\
1(1.1 \%)\end{array}$ & 0.601 \\
\hline $\begin{array}{l}\text { Ki67 } \\
\quad<3 \% \\
\quad 3 \%-20 \% \\
>20 \%\end{array}$ & $\begin{array}{l}6(54.5 \%) \\
5(45.5 \%) \\
0(0 \%)\end{array}$ & $\begin{array}{l}41(65.1 \%) \\
21(33.3 \%) \\
1(1.6 \%)\end{array}$ & 0.652 \\
\hline LVI & $4(50.0 \%)$ & $24(27.0 \%)$ & 0.332 \\
\hline PNI & $1(20.0 \%)$ & $8(9.9 \%)$ & 1.0 \\
\hline Lymph node positive & $7(50.0 \%)$ & $20(27.8 \%)$ & 0.185 \\
\hline $\begin{array}{l}\text { Resection status } \\
\text { R0 } \\
\text { R1 }\end{array}$ & $\begin{array}{l}9(52.9 \%) \\
8(47.1 \%)\end{array}$ & $\begin{array}{l}91(84.3 \%) \\
17(15.7 \%)\end{array}$ & 0.007 \\
\hline
\end{tabular}

Abbreviations: LVI, lymphovascular invasion; PNI, perineural invasion

time of presentation. ${ }^{2}$ Even with this more aggressive histopathological tumor type, patients may benefit from surgery with improvement in symptom control and increased survival. ${ }^{22}$ Patients with functional NETs in the background of hereditary tumor syndromes have also been described to have worse prognoses, due to the presence of multifocal tumors which occur earlier in age. Multiple groups have previously demonstrated that in well-selected patients, surgical resection can both alleviate symptoms and increase survival. ${ }^{4,23,24}$ Our study confirmed previous findings that patients with noninsulinoma histology and genetic tumor syndromes have lower RFS. However, when examining these variables together in a multivariable model with failure of symptom improvement after the surgery, only the failure of symptom improvement persisted as being associated with decreased RFS.

In this cohort of functional NETs, symptom control likely serves as a perceptible measure for oncological control. Symptom persistence may represent a manifestation of other oncological parameters, such as micrometastatic disease. This is supported by a mouse study performed by Li et al, in which micrometastases of pancreatic $\beta$-cell tumors express insulin even at distant sites such as the lung and spleen. ${ }^{25}$ In our cohort of patients, who underwent RO resections, however, there was no radiographical, pathological, or surgical evidence which would suggest these patients had residual disease. These findings suggest that symptom persistence after surgery may serve as a strong surrogate marker for persistence of tumor cells within the body. Although there is no current standard adjuvant therapy for patients with functional NETs, as the therapeutic armamentarium grows, it is feasible that symptom persistence after the surgery may be a reasonable selection criterion for patients in future clinical trials. ${ }^{26,27}$ Even more importantly, however, this study demonstrates that patients with symptom persistence may warrant more frequent radiographical surveillance to detect earlier disease recurrence. ${ }^{28}$

The retrospective design and multi-institutional nature of this study pose certain limitations. Capturing complete recurrence data in a retrospective design presented some challenges, as some patients were lost to follow-up. Also, surgical conduct and pathological examination were not standardized across institutions, which may lead to variability in reporting. Further, surveillance strategies were not standardized in this retrospective study which may impact our recurrence rates and timing. Despite these limitations, this study serves as one of the largest in the literature focusing on functional neuroendocrine tumors, as well as symptom control after the surgery. Furthermore, the multi-institutional model captures several

TABLE 5 Univariable and multivariable cox regression analysis examining clinical and pathological factors associated with reduced recurrence-free survival in patients with functional neuroendocrine tumors

\begin{tabular}{|c|c|c|c|c|c|c|}
\hline \multirow[b]{2}{*}{ Variable } & \multicolumn{3}{|c|}{ Univariable } & \multicolumn{3}{|c|}{ Multivariable } \\
\hline & HR & $95 \% \mathrm{Cl}$ & $P$-value & HR & $95 \% \mathrm{Cl}$ & $P$-value \\
\hline \multicolumn{7}{|l|}{ Type of functional tumor } \\
\hline Gastrinoma & 2.8 & $(1.3-6.1)$ & 0.006 & 1.1 & $(0.6-2.0)$ & 0.75 \\
\hline Other (including glucagonoma, somatostatinoma, and VIPoma) & 2.7 & $(1.0-7.2)$ & 0.042 & - & - & - \\
\hline Lymph node positive & 1.8 & $(0.9-3.6)$ & 0.080 & 1.6 & $(0.6-4.6)$ & 0.35 \\
\hline $\mathrm{R} 1$ resection margin & 2 & $(1.0-3.9)$ & 0.052 & 0.45 & $(0.1-1.8)$ & 0.25 \\
\hline Failure of symptom improvement & 3.1 & $(1.3-7.2)$ & 0.008 & 4.7 & $(1.3-16.6)$ & 0.016 \\
\hline
\end{tabular}


(A)

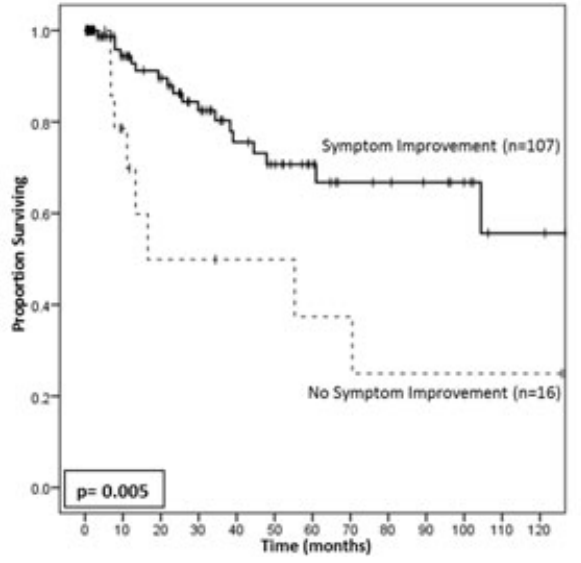

(B)

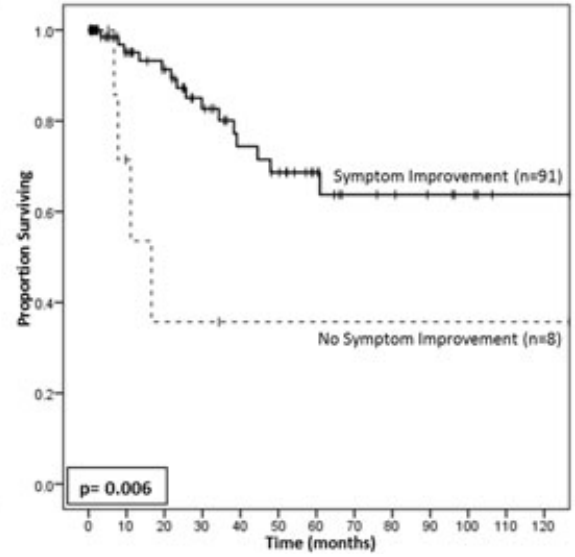

FIGURE 1 Kaplan-Meier plots assessing the association between symptom improvement and recurrencefree survival. For all patients within the study cohort $(A)$, the failure to achieve postoperative symptom improvement was associated with a significantly reduced recurrence-free survival. This remained true when examining only patients with RO resection status on final pathologic assessment (B) institutions and patient populations from a diverse set of geographical regions in the United States.

\section{5 | CONCLUSION}

Patients with functional neuroendocrine tumors who fail to experience hormone-specific symptom improvement after curativeintent surgical resection have worse RFS than those patients who do experience symptom improvement. The failure of symptom improvement likely serves as a perceptible measure of subradiographical residual disease. Patients who fail to have symptom improvement after curative-intent resection may be well-suited to undergo shortinterval radiographical surveillance to detect earlier radiographical recurrence of disease.

\section{CONFLICTS OF INTEREST}

No financial or material disclosures to report.

\section{MEMBERS OF THE US NEUROENDOCRINE TUMOR STUDY GROUP}

Mohammad Y. Zaidi, Alexandra G. Lopez-Aguiar, Kenneth Cardona, and Shishir K. Maithel: Division of Surgical Oncology, Department of Surgery, Winship Cancer Institute, Emory University, Atlanta, GA; Eleftherios Makris and George A. Poultsides: Department of Surgery, Stanford University Medical Center, Stanford, CA; Eliza W. Beal and Mary Dillhoff: Division of Surgical Oncology, The Ohio State University Comprehensive Cancer Center, Columbus, $\mathrm{OH}$; Zaheer S. Kanji and Flavio G. Rocha: Department of Surgery, Virginia Mason Medical Center, Seattle, WA; Paula Marincola Smith and Kamran Idrees: Division of Surgical Oncology, Department of Surgery, Vanderbilt University Medical Center, Nashville, TN; Megan Beems and Hari Nathan: Division of Hepatopancreatobiliary and Advanced Gastrointestinal Surgery, Department of Surgery, University of Michigan, Ann Arbor, MI; James R. Barrett and Emily R. Winslow: Department of Surgery, University of Wisconsin School of Medicine and Public Health, Madison, WI; Bradley A. Krasnick and Ryan C.
Fields: Department of Surgery, Washington University School of Medicine, St Louis, MO.

\section{ORCID}

Mohammad Y. Zaidi (D) http://orcid.org/0000-0002-4246-1724

Alexandra G. Lopez-Aguiar (D) http://orcid.org/0000-0002-7928-4901 Kenneth Cardona (D) http://orcid.org/0000-0002-8200-3269

\section{REFERENCES}

1. Dickson PV, Behrman SW. Management of pancreatic neuroendocrine tumors. Surg Clin North Am. 2013;93(3):675-691.

2. Parbhu SK, Adler DG. Pancreatic neuroendocrine tumors: contemporary diagnosis and management. Hosp Pract (1995). 2016;44(3): 109-119.

3. Anderson CW, Bennett JJ. Clinical presentation and diagnosis of pancreatic neuroendocrine tumors. Surg Oncol Clin N Am. 2016;25(2): 363-374.

4. Cougard P, Goudet P, Peix JL, et al. Insulinomas in multiple endocrine neoplasia type 1. Report of a series of 44 cases by the multiple endocrine neoplasia study group. Ann Chir. 2000;125(2): 118-123.

5. Jensen RT, Berna MJ, Bingham DB, Norton JA. Inherited pancreatic endocrine tumor syndromes: advances in molecular pathogenesis, diagnosis, management, and controversies. Cancer. 2008;113(7 Suppl): 1807-1843.

6. Marx S, Spiegel AM, Skarulis MC, Doppman JL, Collins FS, Liotta LA. Multiple endocrine neoplasia type 1: clinical and genetic topics. Ann Intern Med. 1998;129(6):484-494.

7. Norton JA, Cornelius MJ, Doppman JL, Maton PN, Gardner JD, Jensen RT. Effect of parathyroidectomy in patients with hyperparathyroidism, Zollinger-Ellison syndrome, and multiple endocrine neoplasia type I: a prospective study. Surgery. 1987;102(6): 958-966.

8. O'Riordain DS, O'Brien T, van Heerden JA, Service FJ, Grant CS. Surgical management of insulinoma associated with multiple endocrine neoplasia type I. World J Surg. 1994;18(4):488-493. Discussion 93-4.

9. Roy PK, Venzon DJ, Shojamanesh H, et al. Zollinger-Ellison syndrome. Clinical presentation in 261 patients. Medicine (Baltimore). 2000;79(6): 379-411.

10. Thakker RV. Multiple endocrine neoplasia type 1. Endocrinol Metab Clin North Am. 2000;29(3):541-567. 
11. Zerbi A, Capitanio V, Boninsegna L, et al. Surgical treatment of pancreatic endocrine tumours in Italy: results of a prospective multicentre study of 262 cases. Langenbecks Arch Surg. 2011;396(3): 313-321.

12. Crippa S, Zerbi A, Boninsegna L, et al. Surgical management of insulinomas: short- and long-term outcomes after enucleations and pancreatic resections. Arch Surg. 2012;147(3):261-266.

13. Watzka FM, Laumen C, Fottner C, et al. Resection strategies for neuroendocrine pancreatic neoplasms. Langenbecks Arch Surg. 2013; 398(3):431-440

14. Norton JA. Endocrine tumours of the gastrointestinal tract. Surgical treatment of neuroendocrine metastases. Best Pract Res Clin Gastroenterol. 2005;19(4):577-583.

15. Sarmiento JM, Que FG. Hepatic surgery for metastases from neuroendocrine tumors. Surg Oncol Clin N Am. 2003;12(1):231-242.

16. Sutcliffe R, Maguire D, Ramage J, Rela M, Heaton N. Management of neuroendocrine liver metastases. Am J Surg. 2004;187(1):39-46.

17. Neuroendocrine Tumors. In: Edge SB, Byrd DR, Compton CC, Fritz AG, Greene FL, III, AT, eds. AJCC Cancer Staging Manual. 7th ed. New York: Springer; 2010:pp. 181-185.

18. Chi W, Warner RRP, Chan DL, et al. Long-term outcomes of gastroenteropancreatic neuroendocrine tumors. Pancreas. 2018;47(3): 321-325.

19. Madeira I, Terris B, Voss M, et al. Prognostic factors in patients with endocrine tumours of the duodenopancreatic area. Gut. 1998;43(3): 422-427.

20. Modlin IM, Moss SF, Gustafsson BI, Lawrence B, Schimmack S, Kidd $M$. The archaic distinction between functioning and nonfunctioning neuroendocrine neoplasms is no longer clinically relevant. Langenbecks Arch Surg. 2011;396(8):1145-1156.

21. Phan GQ, Yeo CJ, Hruban RH, Lillemoe KD, Pitt HA, Cameron JL. Surgical experience with pancreatic and peripancreatic neuroendocrine tumors: review of 125 patients. J Gastrointest Surg. 1998;2(5): 472-482.
22. Norton JA, Sugarbaker PH, Doppman JL, et al. Aggressive resection of metastatic disease in selected patients with malignant gastrinoma. Ann Surg. 1986;203(4):352-359.

23. Bartsch DK, Langer $P$, Wild A, et al. Pancreaticoduodenal endocrine tumors in multiple endocrine neoplasia type 1 : surgery or surveillance? Surgery. 2000;128(6):958-966.

24. Norton JA, Fang TD, Jensen RT. Surgery for gastrinoma and insulinoma in multiple endocrine neoplasia type 1. J Natl Compr Canc Netw. 2006;4(2):148-153.

25. Li J, Yang Y, Zhou X, et al. Micrometastasis expressing insulin arise in lung and spleen at advanced stage of rip1-tag2 transgenic mice. Int J Biol Sci. 2014;10(2):136-141.

26. Auernhammer CJ, Spitzweg C, Angele MK, Boeck S, Grossman A, Nölting $S$ et al. Advanced neuroendocrine tumours of the small intestine and pancreas: clinical developments, controversies, and future strategies. Lancet Diabetes Endocrinol. 2018;6(5):404-415.

27. Dimitriadis GK, Weickert MO, Randeva HS, Kaltsas G, Grossman A. Medical management of secretory syndromes related to gastroenteropancreatic neuroendocrine tumours. Endocr Relat Cancer. 2016;23(9): R423-R436.

28. Oberg K, Jelic S, Group EGW. Neuroendocrine gastroenteropancreatic tumors: ESMO clinical recommendations for diagnosis, treatment and follow-up. Ann Oncol. 2008;19(Suppl 2):ii104-ii105.

How to cite this article: Zaidi MY, Lopez-Aguiar AG, Poultsides GA, et al. The impact of failure to achieve symptom control after resection of functional neuroendocrine tumors: An 8-institution study from the US Neuroendocrine Tumor Study Group. J Surg Oncol. 2019;119:5-11. https://doi.org/10.1002/jso.25306 